\title{
Proyecto Educativo y Educación Integral en el Colegio Santa Isabel de Hungría
}

\author{
Jaime Caiceo Escudero \\ Universidad de Santiago de Chile - USACH, Chile \\ Colegio Santa Isabel de Hungría, Chile
}

\begin{abstract}
RESUMO
O projeto educativo institucional reflete o tipo de educação que se deseja desenvolver. Neste contexto, é apresentada neste trabalho a proposta da escola Santa Isabel de Hungría da comuna de La Cisterna em Santiago do Chile. Ela persegue una educação integral, inspirada pelo humanismo cristão como referência filosofico-educacional. Os resultados dos últimos anos com indicadores internos e externos também são expostos. O que se expõe é resultado de uma pesquisa empírica de caráter analítico e avaliativo no contexto de um estudo de caso.
\end{abstract}

PALAVRAS-CHAVE: Projeto educativo institucional. Filosofia humanista cristã. Educação personalista. Experiência em escola confessional gratuita.

\section{EDUCATIONAL PROJECT AND COMPREHENSIVE EDUCATION AT THE SAINT ELIZABETH OF HUNGARY SCHOOL}

\begin{abstract}
The institutional educational project reflects the type of education that you want to deliver. In this context is presented in this work proposal of the school Saint Elizabeth of Hungary of the commune of La Cisterna in Santiago de Chile. It pursues an integral education, inspired by the Christian humanism as educational philosophy reference. The results of recent years with internal and external indicators are also delivered. What is presented is the result of an empirical investigation of analytical and evaluative character in the context of a case study.
\end{abstract}

KEYWORDS: Institutional educational project. Christian humanist philosophy. Personalist education. Experience in confessional school free.

\section{PROYECTO EDUCATIVO Y EDUCACIÓN INTEGRAL EN EL COLEGIO SANTA ISABEL DE HUNGRÍA}

\section{RESUMEN}

El Proyecto Educativo Institucional refleja el tipo de educación que se desea entregar. En ese contexto se presenta en este trabajo la propuesta del colegio Santa Isabel de Hungría de la comuna de La Cisterna en Santiago de Chile. Persigue una educación integral, inspirado en el humanismo cristiano como referencia filosófico-educacional. Se entregan asimismo los resultados de los últimos años con indicadores internos y externos. Lo que se presenta es el resultado de una investigación empírica de carácter analítico y evaluativo en el contexto de un estudio de caso. 
ESCUDERO, J.C.

PALABRAS CLAVE: Proyecto Educativo Institucional. Filosofía humanista cristiana, Educación personalista. Experiencia en colegio confesional gratuito.

\section{INTRODUÇÃO}

Generalmente cuando se habla de educación se indica que debe ser integral sin precisar lo que ello significa. Una educación integral persigue el desarrollo espiritual, moral, cognitivo, afectivo y físico de la persona del alumno. Donde mejor se precisa ello es en el Proyecto Educativo Institucional (PEI) de cada colegio (CAICEO, 1996). En este caso, se analizará el PEI de un colegio confesional que ha elaborado el Proyecto con la participación de toda la comunidad educativa hace años, actualizándolo periódicamente. Su fundamento teórico es el humanismo cristiano, el cual concibe al ser humano como persona compuesta de un cuerpo y un espíritu y, a ese ser, hay que educarlo integralmente.

El objetivo de esta ponencia en analizar el PEI indicado y cuál ha sido el resultado hasta la fecha. La población beneficiada está compuesta por 1200 alumnos. La metodología, propia de un estudio de caso -como el estudiado- es cualitativa con elementos cuantitativos, complementada con aspectos propios del análisis y la evaluación; para esta última se utilizarán elementos externos e internos; externo ha sido el Ministerio de Educación de Chile que ha otorgado por 14 años la excelencia pedagógica al establecimiento; los internos son la evaluación de satisfacción que se aplica a los apoderados y los resultados académicos de los propios alumnos en pruebas SIMCE para medir la calidad de los resultados -realizadas por el estado- y PSU -prueba para ingresar a la educación superior, realizada por una universidad pública-. Este estudio también es investigación-acción, pues el investigador forma parte del establecimiento estudiado. La evidencia de los resultados se encuentra en los antecedentes que se expondrán in extenso más adelante.

\section{DESCRIPCIÓN DEL COLEGIO SANTA ISABEL DE HUNGRÍA}

Por tratarse de un estudio de caso, se describen primeramente los orígenes y caracterización del colegio Santa Isabel de Hungría; fue fundado en la comuna semi-rural de La Cisterna en 1961 por la Superiora de la Congregación Religiosa Hermanas Franciscanas Cooperadoras Parroquiales, Madre Teresa Ortúzar Ovalle (CAICEO, 2017).

Esta religiosa había nacido en Santiago de Chile el 31 de julio de 1882 como María Carolina Sara Ignacia Ortúzar Ovalle; sus padres fueron Carlos Ortúzar Montt y Tránsito Ovalle Fernández; el origen de ambos era aristocrático. Por lo mismo, cuando aún no cumplía un año María Carolina, sus padres viajaron a Europa, visitando varios países, entre ellos Italia, Francia, 
España, Suiza y Alemania, cambiando constantemente de residencia hasta que finalmente se instalaron en Italia; allí nacieron otros hijos. La pequeña María Carolina tuvo varias maestras de diferentes nacionalidades: alemanas, francesas, inglesas e italianas.

Un año antes de la Revolución de $1891^{1}$ que aconteció en el país, regresó a Chile siendo aún una niña, prosiguiendo sus estudios, ahora en forma sistemática.

Antes de cumplir los dieciocho años de edad, el 9 de junio de 1900, ingresó al Claustro de las Carmelitas Descalzas en San Bernardo, ciudad aledaña a Santiago; allí tomó el nombre religioso de Teresa. En ese lugar de oración, penitencia y sufrimiento no duró mucho, pues se enfermó y se retiró. Sin embargo, sus meditaciones la condujeron a pensar en fundar una institución que se dedicara a trabajar con los niños pobres. Para concretar su idea viajó a la ciudad de Antofagasta -ciudad Puerto-, distante 1.350 kms. de la capital; el Obispo del lugar, Monseñor Luis Silva Lazaeta, la ayudó a fundar las Hijas del Salvador, Reparadoras del Santísimo Sacramento. Por los problemas económicos existentes, las primeras religiosas se dedicaron a pedir limosna, lo cual no fue comprendido por las autoridades y debió trasladar su comunidad a otras ciudades como Tocopilla, Taltal y Pisagua.

Un poco angustiada viajó a Roma a entrevistarse con el Papa Pío XI, quien la animó a proseguir su obra. Al volver, sin embargo, encontró a su institución en el abandono y la miseria. Desilusionada se trasladó a Lomas de Zamora en la Provincia de Buenos Aires en 1937. A pesar del apoyo del Obispo del lugar, tuvo conflictos con otras religiosas de allí y regresó a Chile en 1940.

En esta ocasión se instaló en la Diócesis de San Felipe de Aconcagua, distante a solo 80 kms. de Santiago. Hizo amistad con el Obispo, Monseñor Roberto Bernardino Berríos Gaínza -miembro de la Orden Franciscana- (Olivares, 1995), quien valoró su trabajo y la acogió. Después de cuatro años de observación, el Pastor le concedió el decreto de fundación de una nueva Congregación. De esta forma, surgió la Pía Unión de las Cooperadoras Parroquiales de la Inmaculada Concepción, Terceras Franciscanas con fecha 8 de diciembre de 1944. Textualmente se lee en el Decreto:

Venimos a fundar en nuestra Diócesis de San Felipe de Aconcagua la Pía Unión de las Cooperadoras Parroquiales de la Inmaculada Concepción, Terceras Franciscanas el 8 de diciembre de 1944, formando de esa manera la nueva Congregación denominada: 'Hermanas Franciscanas Cooperadoras Parroquiales' (ARCHIVO DIOCESANO: p. 128 del Libro de DECRETOS).

\footnotetext{
${ }^{1}$ Conflicto armado ocurrido en Chile entre partidarios del Congreso Nacional contra los del presidente de la República José Manuel Balmaceda; en el fondo, era un conflicto de poderes entre el legislativo y el ejecutivo. Tras las batallas de Concón y Placilla, las fuerzas leales al presidente fueron derrotadas y el Presidente asilado en la Embajada Argentina, se suicidó.
} 
Por sugerencia del Obispo Franciscano, consideraron como modelo de vida a San Francisco de Asís, quien enfatizó al Cristo pobre y humilde. En una primera etapa, las nuevas religiosas se dedicaron a colaborar con las Parroquias.

La Hermana Mercedes, ya fallecida, recuerda los inicios y la estrecha relación entre la Madre Teresa y el Obispo:

[...] él vio que Nuestra Madre quería juntar juventud para formarla y Monseñor tenía sus ideas; así unen estas ideas. Él dijo que estaba bien y las apoyó. Venía cada quince días a darnos formación, a darnos instrucciones y él quería que fuéramos de vida activa, que estuviésemos con la gente, que los visitáramos y él, como era un misionero todo el año, visitaba sus Parroquias hasta el Choapa. Llegaba a toda su Diócesis, a sus Iglesias, constatando que estaban muy abandonadas, buscaba las soluciones; nosotras colaborábamos (MUÑOZ, 2002, p. 2).

La Casa Generalicia se instaló en la ciudad de Los Andes, distante solo 18 kms. de San Felipe. Entre las diferentes obras que realizaba la nobel congregación se encontraba la educación. De esta forma, apoyaban a las Escuelas Parroquiales ${ }^{2}$, las cuales atendían a los niños más pobres; fue así como trabajaron en las escuelas en Panquehue, Zapallar, Curimón y Putaendo, todas de la zona de Aconcagua. Esto sirvió para que simultáneamente la Madre Teresa (SOCÍAS, 2010) fundara dos establecimientos educacionales propios en 1961: El Colegio Santa Clara, ubicado en la población Centenario ${ }^{3}$ de la ciudad de Los Andes, y el Colegio Santa Isabel de Hungría en la comuna de La Cisterna ${ }^{4}$ en la Región Metropolitana. En estos establecimientos educacionales se preparaba a los niños y niñas en las primeras letras y en los números, pero especialmente en la entrega de valores y en la práctica de la fe. Con esta actividad se ayudaba a las familias más pobres, educando con un carisma especial, que era muy bien recibido por las comunidades escolares; lo más relevante es que en una época en que los colegios católicos eran para hombres o para mujeres (antes del Concilio Vaticano II), la Madre Fundadora estableció establecimientos mixtos (CAICEO, 2010b).

La historia del Colegio Santa Isabel de Hungría puede dividirse en tres períodos: (i) 1961-1991: La dirección siempre estuvo a cargo de una religiosa de la congregación (10 en total); en este período se adquirieron cinco lotes de terreno para poder ir construyendo por partes; se inició con la educación primaria (6 años de escolaridad), como Escuela

\footnotetext{
${ }^{2}$ El Director Supremo de Chile entre 1818 y 1823, Bernardo O'Higgins, para empezar a consolidar en el plano educativo a la naciente república, ordenó que en cada Parroquia se estableciera una escuela. Hay que tener presente que no había separación Iglesia-Estado y, por lo tanto, los Párrocos eran funcionarios públicos; además eran los que estaban más preparados para educar. Sólo en 1842 se fundó la Primera Escuela de Preceptores para formar maestros (CAICEO, 2010a).

${ }^{3}$ Estaba junto a la ciudad y albergaba a familias de menores ingresos.

${ }^{4}$ Era una comuna nueva, semi rural; poseía dos establecimientos católicos pagados, pudiendo acceder a ellos, hijos de familias más acomodadas; por lo mismo, la Madre Teresa quiso formar un colegio gratuito para los hijos de familias vulnerables.
} 
Subvencionada $N^{\circ}$ 447, a través del Decreto del Ministerio de Educación $N^{\circ} 17.493$ del día 13 de noviembre de 1961, que pronto se transformará en educación básica (8 años de escolaridad, considerando la reforma de 1965 (CANALES, 1997); la primera Directora fue la Hna. Paula Hernández; en 1978, siendo Directora la Hna. Rosario Valdivia, se incluyó la educación media (4 años de escolaridad), gracias al Decreto del Ministerio de Educación $N^{\circ} 2.521$ del 26 de junio de 1978; se inicia un curso paralelo por nivel, alcanzando en el período cerca de 900 alumnos; la consolidación del carisma franciscano al interior del establecimiento fue lo más relevante; por lo mismo, el colegio era gratuito para los alumnos, financiado por el estado; existió un gran apoyo de los Centros de Padres y Apoderados. (ii) 1992-1997: El establecimiento es cedido en comodato al Arzobispado de Santiago por 6 años renovables, considerando la escasez de religiosas para asumir la dirección; en este período hay dos personas laicas que asumen la dirección; el establecimiento se integra al financiamiento compartido ${ }^{5}$ creado por el gobierno en 1993; la gestión no es la esperada por las religiosas y, por ello, no se renueva el comodato. (iii) 1998 a la fecha: El establecimiento es dirigido por un grupo de tres laicos, quienes asumen la Dirección, Subdirección y Administración ${ }^{6}$; se construye de nuevo el $80 \%$ del establecimiento ${ }^{7}$, incorporando tecnología en las salas de clases (PC y data en una primera etapa y luego pizarras interactivas en los cursos menores y Pantalla de Televisión manejada con iPad por los docentes en los cursos superiores); se habilitan un laboratorio de ciencias con tecnología de punta y dos laboratorios de computación (CAICEO, 2010b); se adquieren más terrenos aledaños en el 2014, en los cuales se instalan un polideportivo con cancha de baby-football y un patio con pasto sintético implementado con máquinas de ejercicio; el alumnado llega a 1200 distribuido en 28 cursos desde Pre-Kinder hasta IV Año Medio; desde

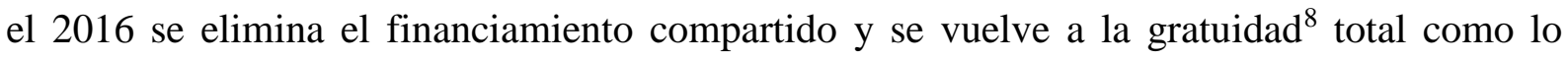
deseaba la fundadora; se incorpora el colegio a dos programas financiados por el estado a fin de atender mejor a los estudiantes: PIE (Programa de Integración Escolar para apoyar a los alumnos con diferencias específicas) y SEP (Subvención Escolar Preferencial para establecer un Plan de Mejora a fin de apoyar con acciones especiales a los alumnos más carenciados económicamente); se enfatiza la acción pastoral y se vuelve a tener un gran apoyo de los Centros

\footnotetext{
${ }^{5}$ El colegio sigue recibiendo el aporte del estado, vía subvención escolar, pero puede cobrar una suma adicional a los apoderados; en todo caso, la mensualidad en el establecimiento era baja: no excedía de los US\$40, cuando la ley permitía sobre los US\$120.

${ }^{6}$ Sus nombres son Dr. Jaime Caiceo Escudero, Magíster Ana María Carrizo Guitérrez y Sofía Bustos Larenas, Contadora Auditora, respectivamente.

${ }^{7}$ Para lograr parte del financiamiento $(30 \%)$ se recurre a un programa de gobierno que financiaba reconstrucción de establecimientos educacionales para lograr instalar la jornada escolar completa establecida en 1996; en el 2004 se inauguran en presencia del Ministro de Educación, las nuevas dependencias.

${ }^{8}$ Gracias a ley de inclusión promulgada el año anterior, la cual elimina la selección de alumnos, el financiamiento compartido y el lucro.
} 
ESCUDERO, J.C.

de Padres; se incentiva la elección de Centros de Alumnos; se elabora un Proyecto Educativo propio en el 2000 y se actualiza en el 2015 (COLEGIO SANTA ISABEL DE HUNGRÍA, Anuarios 2000-2018).

\section{PROYECTO EDUCATIVO INSTITUCIONAL}

La necesidad de que todo establecimiento educacional tenga un Proyecto Educativo Institucional -PEI- se remonta en Chile a la década del 60 del siglo pasado, cuando producto del Concilio Vaticano II (1962-1965), una serie de congregaciones religiosas dejaron las escuelas y colegios que regentaban para irse a las poblaciones a realizar su labor pastoral, entregando sus unidades educativas al Arzobispado de Santiago u otras Diócesis del país. En vista de ello, el Cardenal Raúl Silva Henríquez fundó en la Arquidiócesis de Santiago la Vicaría para la Educación, trayendo de Italia al sacerdote salesiano P. Víctor Gambino como Vicario. Con las ideas existentes en Europa, el nuevo Vicario comienza a impulsar la necesidad de que cada establecimiento educacional tuviera su propio PEI (CAICEO, 1996).

Por ello, a los dos años de haber asumido la Dirección del equipo enunciado anteriormente se elaboró el primer PEI institucional del Colegio Santa Isabel de Hungría (2000) con la participación democrática de los tres estamentos: docentes, alumnos y padres y apoderados. Como desde esa época en adelante hubo varios cambios educacionales a nivel internacional y de políticas a nivel nacional, durante el año 2015 se sometió el PEI a una revisión y reactualización también con la participación de representantes de la comunidad educativa. De esta forma, se publica al año siguiente entregándole un ejemplar a cada funcionario del colegio y a cada familia con estudiantes en el mismo; a su vez, se sube a la página web del establecimiento.

La Superiora de la Congregación, Hna. Bernarda Madariaga Urzúa, en la Presentación del PEI, señala expresamente los conceptos de educación de calidad y formación integral de la persona, motivo de este trabajo:

La complejidad de una sociedad moderna nos convence de cuán importante y necesario es dar relevancia a la conciencia de la identidad Eclesial de la Escuela Católica, identificando las características fundamentales del Proyecto Educativo, que nos permite evaluar, conocer sus fortalezas y debilidades y a partir del análisis de la misma, elaborar planes de mejora que fortalezcan y garanticen una Educación de Calidad, entendida como el logro de Aprendizajes Académicos, de habilidades y de Identidad Católica, buscando como objetivo la formación integral de la persona (MADARIAGA en Congregación Religiosa Hermanas Franciscanas Cooperadoras Parroquiales, 2016, p. 6). 
El Director, a su vez, en la fundamentación del PEI especifica claramente la educación integral:

Cuando se habla de educación integral, ella se percibe como un proceso educativo que abarca los diferentes ámbitos de la vida: espiritual, personal, social, afectivo $y$ cognitivo lo que incluye el desarrollo de actitudes, experiencias, hábitos y valores que posibiliten la formación (CAICEO en Congregación Religiosa Hermanas Franciscanas Cooperadoras Parroquiales, 2016: p. 7).

El motivo central del PEI del Colegio Santa Isabel de Hungría es la persona del alumno o alumna que recibe y atiende. Es el pensamiento cristiano que, a través de San Agustín, a inicios de la Edad Media, introduce tal concepto en el lenguaje filosófico para referirse al ser humano como una analogía de las Tres Personas Divinas del dogma de la Trinidad; en el fondo cuando se dice persona es lo mismo que decir visión cristiana de ser humano, lo que implica concebirlo como un todo compuesto de partes, cuerpo y espíritu y, a su vez, como ser único e irrepetible; por lo mismo, su ser no se agota en sí mismo sino que está abierto a la trascendencia, es decir, a su Creador (CAICEO, 1989).

La persona, por su parte, es un ser en relación consigo mismo, con la naturaleza, con los otros y con Dios, según los filósofos contemporáneos Martín Buber, Gabriel Marcel y Emmanuel Mounier. La relación consigo mismo implica conocerse y aceptarse tal cual uno es, algo muy difícil en la práctica; sin embargo, hay que tender a ello en lo posible. La relación con la naturaleza cobra una especial dimensión en la espiritualidad franciscana, propia del Colegio en estudio, por el amor que San Francisco tuvo con los animales; la persona debe respetar y cuidar su entorno, situación que se hace más necesaria en la sociedad actual por el resguardo de los ecosistemas; el desarrollo actual de la sociedad debe transformarse en un desarrollo sustentable, lo cual implica respetar la naturaleza; no es extraño que el actual Papa Francisco en el 2015 publicara la Encíclica Laudato Si para referirse al cuidado de la Casa Común, nuestro planeta, considerando el calentamiento global que los propios hombres hemos provocado. La relación con los otros se explicita en la denominada relación dialógica yo-tú, en términos filosóficos, y de relación de amor entre hermanos, en lenguaje religioso. La relación de la persona con Dios adviene en la medida que se exprese la relación auténtica entre los hombres en el mundo; no hay que olvidar el mensaje del Apóstol Juan: "Si uno dice `Amo a Dios`, y no ama a su hermano, es un mentiroso. ¿Cómo puede amar a Dios, a quien no ve, y

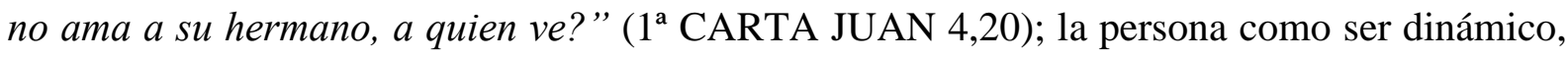
dotado de razón en su espacio de libertad, se constituye en un ser transcendental; es decir, se proyecta más allá de su mundo natural. Creado para un fin sobrenatural para ver a Dios, como Dios se ve, y para llegar a la vida misma de Dios (CAICEO, 1996). 
La persona humana posee una naturaleza racional, por su espíritu, el cual la dota de inteligencia y de voluntad. Por la primera, piensa, razona y crea; por la segunda es un ser libre, lo cual lo hace responsable de sus actos. Surge, de esta forma, la moralidad, condición que le permite discernir en plenitud el bien como todo aquello venido de Dios y que le ayuda en el crecimiento de su ser; a su vez, el mal, como acto consciente y alejado del beneplácito de la Ley Divina le impide su perfeccionamiento en el mundo (CAICEO, 1989).

Por la realidad social y de hermandad cristiana en que vive cada persona, esta debe contemplar a los otros en su proyecto personal de crecimiento; por ello, debe intentar construir un espacio para vivir con el otro que se encuentra a su lado -en el hogar, en el trabajo, en la comunidad de su edificio, etc.- en un clima de respeto, tolerancia y progreso positivo. Respecto a la sociedad, esta es la alianza humana por excelencia, donde las necesidades del hombre alcanzan plena satisfacción, pues, a pesar de todos los avances, es en el grupo social en el cual el ser humano se desenvuelve donde solo puede encontrar un desarrollo más pleno; por ello, la realidad de las personas en la sociedad debe estar enmarcada en un ambiente de justicia, trabajo, progreso y solidaridad, todo lo cual se expresa mejor en democracia; por lo mismo la Iglesia, desde PÍO XII (Radiomensaje de Navidad, 1944) en adelante, ha apoyado la democratización de los pueblos. Ello también debe darse al interior de las escuelas, colegios o liceos, logrando tener directivas de centros de alumnos y de padres y apoderados elegidas por sus pares.

La filosofía franciscana está sintetizada en la Presentación del libro Filosofía Franciscana: Principales Autores en sus Textos

El pensamiento franciscano y, puntualmente esta obra preparada por el Dr. Jaime Caiceo Escudero respecto de esta realidad, obviamente vista desde mi punto de vista, se vuelve profético e incómodo, como el mismo Francisco de Asís fue un hombre místico y profético y como lo ha sido el pensamiento franciscano a los largo de la historia; en donde la paz y el bien; la fraternidad y la libertad; la igualdad y la tolerancia; la justicia y la caridad son valores irrenunciables para aquel que ha experimentado el amor del Padre como Francisco lo experimentó. En este punto se toca un elemento profundamente subversivo y transformador, como es el amor (ESCÁRATE en CAICEO, 2018, Anexo N 4, p. 180).

En el contexto anterior la Visión del Colegio Santa Isabel de Hungría es:

La Comunidad Educativa Santa Isabel de Hungría, fiel a la espiritualidad franciscana, propone transformar al Colegio, mediante un estilo de gestiónanimación, en un espacio abierto a todos, inclusivo-participativo, con una propuesta de calidad educativa y pastoral progresiva, a la luz de los principios evangélicos y carismáticos, con claro desarrollo sostenible en el tiempo. Ello persigue formar a la persona del alumno y de la alumna para ser libres y sociables, que buscan el bien común, que tienen derechos y deberes para con sus semejantes, que están en constante búsqueda de la perfección a través del servicio al prójimo y el amor a Dios (CONGREGACIÓN RELIGIOSA 
HERMANAS FRANCISCANAS COOPERADORAS PARROQUIALES, 2016: p. 26).

Por su parte, la Misión se presenta como:

El Colegio Santa Isabel de Hungría, fiel a la misión evangelizadora de la Iglesia y al carisma de San Francisco de Asís, está comprometido en proveer de herramientas efectivas para la formación integral de los alumnos y alumnas, mediante una sólida educación fundamentada en valores cristianos, en su expresión franciscana que promuevan el desarrollo equilibrado de su afectividad, espiritualidad-trascendencia y el crecimiento social, artístico, afectivo, cognitivo-intelectual, físico y su sensibilidad ecológica (CONGREGACIÓN RELIGIOSA HERMANAS FRANCISCANAS COOPERADORAS PARROQUIALES, 2016: p. 26).

Siguiendo los lineamientos anteriores, la propuesta pedagógica del Colegio Santa Isabel de Hungría se elabora a partir de un conjunto de seis principios generales que conforman la identidad propia que se encuentra presente en su PEI, a saber, (i) Educación Comunitaria; (ii) Educación Inclusiva; (iii) Educación Integral; (iv) Innovación y Excelencia Pedagógica; (v) Ambiente Educativo y (vi) Educación Participativa y Democrática (CONGREGACIÓN RELIGIOSA HERMANAS FRANCISCANAS COOPERADORAS PARROQUIALES, 2016: p. 20).

En el mismo PEI se van precisando:

Educación Comunitaria: ... Ello significa que la comunidad es parte protagónica de la gestión del colegio... El Colegio es un espacio que acoge a la comunidad en su conjunto, convirtiéndose en un centro de participación y convivencia de la comunidad en su conjunto.

Educación Inclusiva: el Proyecto Educativo está abierto a todas las diferencias y diversidades sociales, culturales, ideológicas, religiosas y de género...

Educación Integral: el Proyecto Educativo asume el desafío de educar a los niños, niñas y jóvenes en multidimensionalidad o integralidad, es decir, propender a un trabajo pedagógico armonioso con las dimensiones espirituales, éticas, psico-afectivas, cognitivas, estéticas, socio-políticas, biológico-corporales y de conciencia ecológica.

Innovación y Excelencia Pedagógica: el Proyecto Educativo, coherente con sus principios generales, desarrolla una pedagogía innovadora, recogiendo lo mejor de diversas tradiciones pedagógicas, así como avances contemporáneos en materia didáctica y tecnológica. El PEI contempla el trabajo de la transversalidad entre valores cristiano-católicos, ciudadanos y los saberes disciplinarios; el uso de la ciudad y la comunidad como recursos pedagógicos; los procesos de co-construcción del saber; formas de evaluación no punitivas, sino formativas; entre muchas otras.

Ambiente Educativo: La Comunidad Educativo Pastoral se esfuerza por vivir y trabajar en un ambiente y estilo educativo franciscano, optando por acoger a los niños, niñas y jóvenes, prioritariamente a los más pobres y necesitados, siendo fieles al legado de nuestra fundadora.

Educación Participativa y Democrática: el Colegio deberá ser una escuela de democracia, de aprendizaje de los derechos humanos, de diálogo y respeto mutuo. Su estructura de administración y gestión es profundamente 
Tal como se indicó precedentemente, la filosofía franciscana está enraizada en la vida humana misma y, por lo mismo, su pedagogía está enmarcada en los valores humano-cristianos que apremia a todos y a cada uno de sus miembros de la comunidad educativa, a saber, testimonio, identidad y compromiso.

Esta pedagogía exige del docente ser dinamizador y permanente evangelizador, puesto que el educando es el centro del proceso educativo, el padre de familia la esencia formativa y participativa y la sociedad el espacio donde se conceptualiza y proyecta la educación impartida (CONGREGACIÓN RELIGIOSA HERMANAS FRANCISCANAS COOPERADORAS PARROQUIALES, 2016, p. 26).

Los valores franciscanos se sintetizan en cuatro principales, a saber, fraternidad, justicia, orden y respeto, todos centrados en un punto central, que es el amor, el centro del evangelio de Jesucristo que hizo carne y vivenció Francisco de Asís. De los cuatro principales surgen una serie de otros valores que se presentan en la Figura $\mathrm{N}^{\circ} 1$.

Figura 1: Los Valores Franciscano.

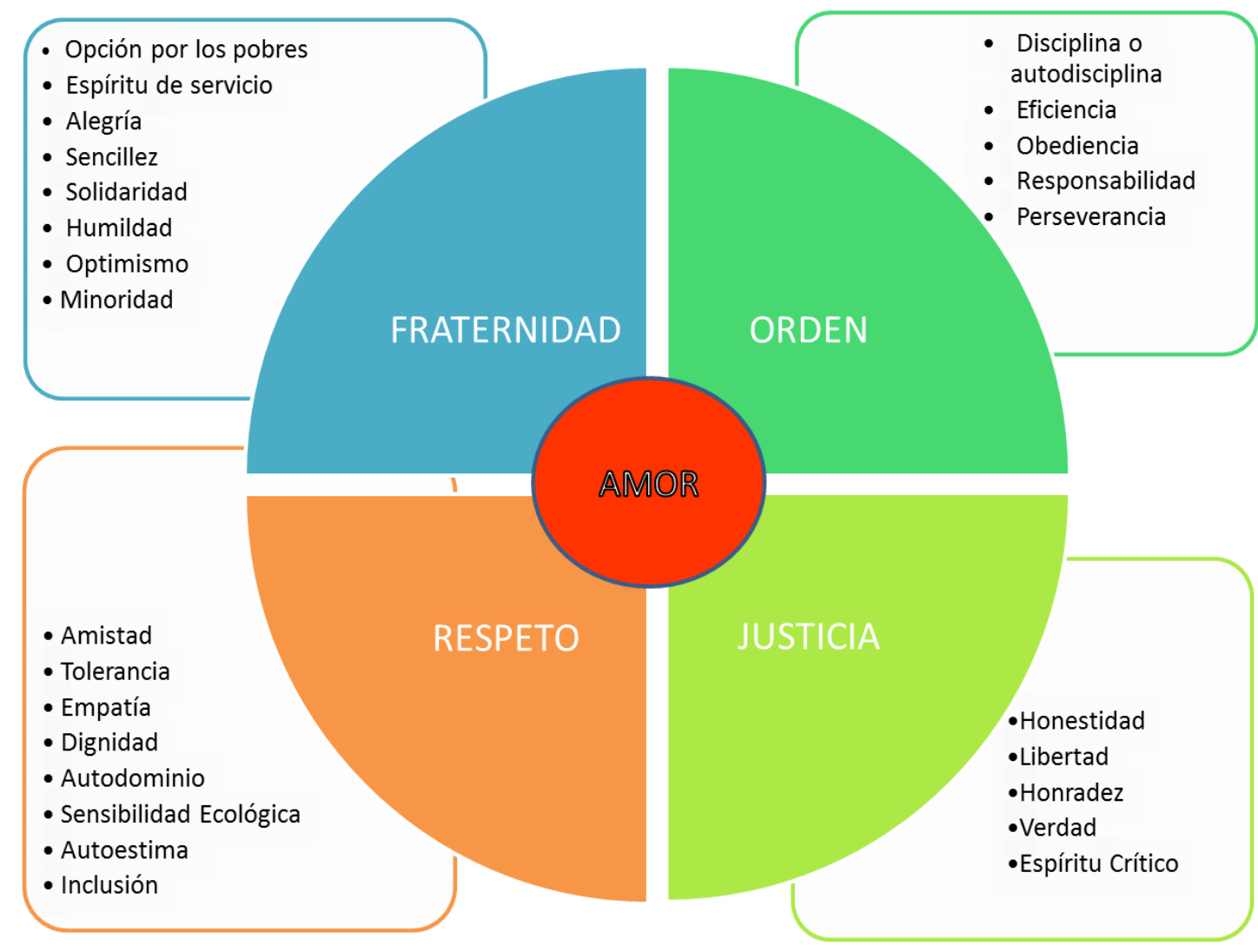

Fuente: PEI Colegio Santa Isabel de Hungría, p. 27 
La fraternidad debe darse con la humanidad y la creación entera; la justicia debe estar presente al reconocer y respetar la dignidad de toda persona; el orden se entiende como la paz universal y en cada comunidad educativa, siguiendo el mensaje franciscano de 'Paz y Bien'; el respeto es con la humanidad toda y la creación en su totalidad (CONGREGACIÓN RELIGIOSA HERMANAS FRANCISCANAS COOPERADORAS PARROQUIALES, 2016).

\section{ACCIONES Y RESULTADOS DE LOS ÚLTIMOS 20 AÑOS}

La política iniciada por la actual Dirección en 1998 ha centrado su quehacer sobre la base de tres dimensiones: (i) acción pastoral, (ii) académica o pedagógica y (iii) recursos educativos, infraestructura y administración.

Por medio de la Acción Pastoral se desea transmitir a toda la comunidad escolar los principios y valores propios del humanismo cristiano, vale decir, el amor, el respeto, la paz y la fraternidad, vividos a la luz del carisma franciscano, todo lo cual se encuentra en su PEI. A su vez, la Pastoral contempla la formación en la fe cristiana de los educandos a través de las clases de religión, retiros, vivencia de la Eucaristía, preparación para recibir los sacramentos (Bautismo, si es necesario, Penitencia, Eucaristía y Confirmación, tanto para los alumnos como para los apoderados), con el fin de formar a los educandos en valores y principios de la fe cristiana.

A través de lo Académico se persigue mejorar significativamente el aprendizaje de los educandos. Para ello, se ha postulado a una serie de planes de mejoramiento, tales como: Programa de Integración Escolar -PIE-, Programa de Subvención Escolar Preferencial -SEP-, Programa Municipal del Servicio Nacional para la Prevención y Rehabilitación del Consumo de Drogas y Alcohol -SENDA-, Programa de Computación ENLACES, Programa Salud de la Junta Nacional de Auxilio Escolar y Becas -JUNAEB-; Programa del Centro Comunitario de Salud Mental -COSAM- y Programa de Sexualidad y Afectividad 'TEEN STAR'. Todo el desarrollo académico del Colegio ha estado circunscrito a las políticas implementadas por el Ministerio de Educación en el contexto de la Reforma Educacional de 1996 del gobierno de Eduardo Frei Ruiz-Tagle y la iniciada en el gobierno de Michelle Bachelet en el 2014 y los lineamientos entregados por la Conferencia Episcopal de Chile.

La labor docente para cumplir adecuadamente su objetivo necesita de recursos y medios pedagógicos como una manera de optimizar el aprendizaje de los estudiantes. A continuación se enumeran algunos de ellos: 1998: Implementación del primer laboratorio de Computación; 2000-2004: Construcción de dependencias para Jornada Escolar Completa -JEC-; 2006: Se 
ESCUDERO, J.C.

construye el rincón de la fe; se adquieren más equipos para el laboratorio de computación, conectados a Intranet e Internet; se implementa un control electrónico para préstamos de libros en el Centro de Recurso de Aprendizaje CRA (antigua biblioteca), la cual recibe una importante donación de libros y otros recursos de aprendizaje; 2007: Se obtienen notebook y data, para que puedan ser trasladados y utilizados en las salas de clases; se contrata red inalámbrica (sistema WI FI); 2008: A través del Programa de Subvención Escolar Preferencial -SEP- se inicia trabajo con alumnos y alumnas vulnerables, prioritarios y con necesidades educativas especiales a través de un Plan de Mejora; se realiza reconstrucción de baños de alumnos; 2009: Se inicia Programa de Mejoramiento Educativo de la Comprensión Lectora; 2010: Se habilita el laboratorio $\mathrm{N}^{\circ} 2$ de Computación; se implementa el trabajo con computadores en biblioteca; 2011: Se obtienen licencias del programa de Computación Matemática -COMPUMAT-; se participa como colegio en el torneo Patrimonio de la Familia, organizada por el Club Deportivo Audax Italiano; se inicia la instalación de equipos multimedia (PC, proyectores, telón y parlantes) en los niveles Pre-Escolar y Primer Ciclo Básico; 2012: Se adquieren pizarras interactivas, para la enseñanza básica desde el nivel Pre-Escolar hasta sexto básico; se prosigue la instalación de equipos multimedia en el Segundo Ciclo Básico; 2013: Se termina la instalación de equipos multimedia en la Enseñanza Media; 2015: Instalación de recursos Tic's de última generación en las salas de $7^{\circ}$ básico a IV medio: Smart Tv; 2015: Se implementa una 'zona de juego, recreación y vida saludable' en el polideportivo para lo cual se adquiere un terreno cercano a los 2.000 metros cuadrados; 2016: Instalación de Smart Tv en salas de Quinto y Sexto Básico, Biblioteca y Laboratorio de Ciencias; 2017: Instalación de Smart Tv Gimnasio del Colegio; 2018: Adecuación de una sala acústica para música. En este período ha existido, a su vez, un constante perfeccionamiento de los docentes, especialmente por organismos externos, universidades y ATE -Agencia Técnica en Educación-, entidades registradas ante el Ministerio de Educación; con ello se ha puesto al día a los profesores en nuevas teorías y planteamientos educacionales, en diferentes aspectos técnicos, como el uso de las Tics en la sala de clase como medio pedagógico y en técnicas para lograr una mejor convivencia escolar (COLEGIO SANTA ISABEL DE HUNGRÍA Memorias 2000-2018).

Desde el punto de vista administrativo-financiero, el establecimiento cumple con toda la legislación laboral y aplica el modelo de gestión financiera propuesto en CAICEO (1997), el cual establece que para mantener una economía sana en los establecimientos educacionales, los gastos deben distribuirse, según sus ingresos normales, en no más del 70\% en personal, $20 \%$ en inversión y 10\% en administración; la inversión es imprescindible en la sociedad actual para mantener los medios pedagógicos actualizados, considerando los avances vertiginosos de la ciencia y la tecnología. Esto ha significado que el establecimiento está sin deudas y mantiene 
los medios pedagógicos más avanzados, como ha quedado demostrado con lo señalado en el párrafo anterior. Para la construcción de dependencias para la Jornada Escolar Completa se recibió un aporte del estado que se devuelve manteniendo en funcionamiento el establecimiento educacional por 15 años, plazo que ya se cumplió (COLEGIO SANTA ISABEL DE HUNGRÍA, Memorias 1998-2017).

La población beneficiada en forma directa por la acción educativa del colegio Santa Isabel de Hungría está compuesta por 1.200 estudiantes y 2.400 padres y apoderados; el origen socio-económico es de clase media baja con una vulnerabilidad determinada por el Ministerio de Educación de 60,51\% para la enseñanza básica y de 55,21\% para la enseñanza media. Esto es importante tenerlo presente, pues llegan muchos muy carenciados en diversos aspectos y el establecimiento debe lograr que las superen y tengan valores y aprendizajes significativos.

Con los antecedentes entregados, el análisis y la evaluación interna, revelan que el establecimiento cumple con entregar una educación impregnada de valores, expresado en el respeto que se tiene por los estudiantes al mantenerles un establecimiento con infraestructura nueva y dotado de la mejor implementación posible para que se sientan a gusto (amplios patios cubiertos y descubiertos, canchas de pasto sintético con máquinas para ejercicios, actividades deportivas, musicales y artísticas complementarias) y reciban con medios pedagógicos de punta el mejor aprendizaje posible; su organización estudiantil permite que sus dirigentes sean elegidos democráticamente; se les enseña a cuidar el medio ambiente y se les ha dotado de un sistema de reciclaje en los patios para que aprendan a cuidar su 'casa común', en palabras del Papa Francisco. Existen, a su vez, dos equipos de profesionales muy importantes: uno para cubrir las necesidades especiales de cerca del 25\% del alumnado (10 profesionales educadoras diferenciales, psicóloga y fonoaudióloga) y otro para mantener la convivencia escolar solucionando los conflictos que puedan originarse y realizar la acción social con los miembros de la propia comunidad escolar (psicólogo, asistente social, mediadora de conflictos. orientadora familiar y vocacional).

Los Padres, Apoderados y Exalumnos reconocen la calidad del colegio y que entrega una educación integral. Ello se demuestra con la alta demanda de matrícula todos los años y, por lo mismo, mantener el máximo de capacidad autorizada por la Secretaría Ministerial de Educación en los últimos 10 años; a su vez, un porcentaje cercano al tercio de los Padres de los estudiantes son Exalumnos. En el Consejo Escolar ${ }^{9}$-existente legalmente desde el 2005 en los establecimientos educacionales, conformado por un representante del sostenedor ${ }^{10}$, el director,

\footnotetext{
${ }^{9}$ Creados a través de la Ley No 19.979 del 6 de noviembre de 2004 para comenzar a operar durante el año escolar (marzo de cada año a febrero del siguiente) 2005.

${ }^{10}$ Entidad que patrocina un establecimiento educacional.
} 
ESCUDERO, J.C.

un representante del consejo de profesores, un representante de los asistentes de la educación ${ }^{11}$, el presidente del centro de padres y apoderados y el presidente del centro de alumnos; debe funcionar cuatro veces al año-, permanentemente los representantes de los docentes y asistentes de la educación reconocen los avances que el colegio ha ido teniendo en forma sostenida en el período en estudio; por su parte, el presidente del centro de padres, agradece la educación que el establecimiento está entregando, especialmente en lo valórico; y el presidente de los alumnos valoran el clima de compañerismo existente y agradecen la infraestructura que poseen con salas muy bien implementadas y patios amplios y confortables para recrearse (COLEGIO SANTA ISABEL DE HUNGRÍA, Informes sobre Rendimiento Escolar 2005-2018).

Los resultados externos, por su parte, especialmente por las pruebas estandarizadas aplicadas por el Ministerio de Educación desde 1988 en Chile, también avalan positivamente el incremento de la calidad académica del colegio Santa Isabel de Hungría. Tales evaluaciones reciben el nombre de SIMCE (Sistema de medición de la calidad de la educación) y persiguen medir los resultados del aprendizaje que los estudiantes poseen en los cuartos básicos, octavos básicos y segundos medios en las asignaturas fundamentales: lenguaje, matemática, historia y ciencias $^{12}$. Hay que considerar que al ser pruebas estandarizadas los estudiantes más vulnerables deben responder lo mismo que los otros alumnos; la alta vulnerabilidad del estudiantado del colegio Santa Isabel de Hungría, ya señalada, por sobre el 50\%, revela por sí mismo que los resultados positivos y de incremento en el período estudiado, son posibles por la aplicación real de los postulados del PEI: una educación de calidad en función de un desarrollo integral de sus beneficiados. Cabe hacer notar que los establecimientos públicos poseen en sus resultados una media bajo los 250 puntos; los colegios de sectores acomodados superan los 300 puntos y el colegio Santa Isabel de Hungría ha subido de resultados en torno a los 240 puntos a una media de 285 puntos $^{13}$. A continuación se muestran en las tablas $\mathrm{N}^{\circ} 1$ y $\mathrm{N}^{\circ} 2$ el histórico del SIMCE en los cuartos básicos y segundos medios del período del establecimiento en estudio:

Tabla 1: Histórico SIMCE 4os. Básicos

\begin{tabular}{l|c|c|c|c|c|l|l|l|l|l}
\hline Año & Lenguaje & & Matemática & & Ciencias & & Historia & & C Medio & \\
\hline 1999 & 242 & & 242 & & & & & & 245 & - \\
\hline 2002 & 281 & +39 & 276 & +34 & & & & & 272 & +27 \\
\hline 2005 & 260 & -21 & 251 & -25 & & & & & 264 & -8 \\
\hline 2006 & 271 & +11 & 282 & +31 & & & & & $\mathbf{2 8 2}$ & +18 \\
\hline 2007 & 275 & +5 & 276 & -6 & & & & & 265 & -17 \\
\hline 2008 & 287 & +12 & $\mathbf{2 8 9}$ & +13 & & & & & 281 & +16 \\
\hline
\end{tabular}

\footnotetext{
11 Corresponde a los profesionales, administrativos, paradocentes y auxiliares de servicio que trabajan en un establecimiento educacional y que no son docentes.

${ }^{12}$ No todas las pruebas se aplican anualmente; los resultados del año 2018 se entregan a comienzos del próximo año.

${ }^{13}$ Ha habido períodos de baja, pero luego se recupera.
} 


\begin{tabular}{l|c|c|c|c|c|c|c|c|c|c}
\hline Año & Lenguaje & & Matemática & & Ciencias & & Historia & & C Medio & \\
\hline 2009 & 284 & -3 & 280 & -9 & & & & & $\mathbf{2 8 2}$ & +1 \\
\hline 2010 & $\mathbf{2 9 2}$ & +8 & 274 & -6 & & & $\mathbf{2 7 6}$ & -5 & & \\
\hline 2011 & 283 & -9 & 282 & +8 & $\mathbf{2 8 2}$ & +6 & & & & \\
\hline 2012 & 280 & -3 & 274 & -8 & & & 266 & -10 & & \\
\hline 2013 & 264 & -16 & 272 & -2 & 264 & -18 & & & & \\
\hline 2014 & 271 & +7 & 265 & -7 & & & 269 & +3 & & \\
\hline 2015 & 266 & -5 & 280 & +15 & & & & & & \\
\hline 2016 & 287 & +21 & 272 & -8 & & & & & & \\
\hline 2017 & $\mathbf{2 9 2}$ & +5 & 284 & +12 & & & & & & \\
\hline
\end{tabular}

Fuente: Unidad Técnico Pedagógica del Colegio Santa Isabel de Hungría (1999-2017)

Tabla 2: Histórico SIMCE Segundos Básicos

\begin{tabular}{l|c|c|c|c|c|c|c|c|c}
\hline 2001 & 246 & -27 & 234 & -28 & & & & & \\
\hline 2003 & 260 & +14 & 241 & +7 & & & & & \\
\hline 2006 & 266 & +6 & 267 & +26 & & & & & \\
\hline 2008 & 283 & +17 & 283 & +16 & & & & & \\
\hline 2010 & 276 & -7 & 273 & -10 & & & & & \\
\hline 2012 & 270 & -6 & 271 & -2 & & & & & \\
\hline 2013 & 277 & +7 & $\mathbf{2 9 7}$ & +26 & & & & & \\
\hline 2014 & $\mathbf{2 8 9}$ & +12 & 296 & -1 & $\mathbf{2 8 5}$ & & & & \\
\hline 2015 & 254 & -35 & 272 & -24 & & & 261 & & \\
\hline 2016 & 259 & +5 & 274 & 2 & 254 & -31 & & & \\
\hline 2017 & 286 & +27 & 294 & +20 & & & 268 & +7 & \\
\hline
\end{tabular}

Fuente: Unidad Técnico Pedagógica del Colegio Santa Isabel de Hungría (1999-2017)

A su vez, existe otra prueba estandarizada que rinden los estudiantes del último año de la enseñanza media y es el requisito para ingresar a las universidades. Se llama PSU -Prueba de Selección Universitaria- y la aplica del DEMRE -Departamento de Evaluación, Medición y Registro Educacional, organismo dependiente de la principal universidad pública del país: la Universidad de Chile. Se aplica en noviembre de cada año a las asignaturas de lenguaje y matemática en forma obligatoria y a historia y ciencias, en forma optativa y de acuerdo a las carreras que el alumno desee postular. El resultado máximo de estas pruebas es 850 puntos; la media en los establecimientos pagados es sobre los 650; el colegio Santa Isabel de Hungría ha ido subiendo de un promedio de 460 puntos a 550 puntos, por sobre establecimientos similares en cuanto al tipo de alumnado que atienden. En Tabla $\mathrm{N}^{\circ} 3$ se entregan los resultados desde el año 2004 en adelante.

Tabla 3: Histórico PSU

\begin{tabular}{c|c|c|c|c|c|c|c|c}
\hline Año & Lenguaje & & Matemática & & Historia & & Ciencias & \\
\hline 2004 & 468 & & 452 & & 461 & & 452 & \\
\hline 2005 & 477 & +9 & 466 & +14 & 505 & +44 & 470 & +18 \\
\hline 2006 & 464 & -13 & 476 & +10 & 484 & -21 & 462 & -8 \\
\hline 2007 & 491 & +27 & 492 & +16 & 499 & +15 & 500 & +38 \\
\hline 2008 & 513 & +22 & 525 & +33 & 508 & +9 & 517 & +17 \\
\hline 2009 & 507 & -5 & 496 & -29 & 501 & -7 & 488 & -29 \\
\hline 2010 & 532 & +25 & 542 & +46 & 533 & +32 & 521 & +33 \\
\hline 2011 & 525 & -7 & 527 & -15 & 525 & -8 & 515 & -6 \\
\hline
\end{tabular}




\begin{tabular}{c|c|c|c|c|c|c|c|c}
\hline Año & Lenguaje & & Matemática & & Historia & & Ciencias & \\
\hline 2012 & 521 & -4 & 508 & -19 & 541 & +16 & 514 & -1 \\
\hline 2013 & 500 & -21 & 496 & -12 & 474 & -67 & 515 & +1 \\
\hline 2014 & 527 & +27 & 509 & +13 & 501 & +27 & $\mathbf{5 4 7}$ & +32 \\
\hline 2015 & 522 & -5 & 531 & +22 & 532 & +31 & 524 & -23 \\
\hline 2016 & 550 & +28 & 546 & +15 & 544 & +12 & 542 & +18 \\
\hline 2017 & 526 & -24 & 534 & -12 & 528 & -16 & 521 & -21 \\
\hline 2018 & $\mathbf{5 5 2}$ & +26 & $\mathbf{5 5 4}$ & +20 & $\mathbf{5 6 0}$ & +32 & 545 & $+24^{14}$ \\
\hline
\end{tabular}

Fuente: Unidad Técnico Pedagógica del Colegio Santa Isabel de Hungría (1999-2018)

Finalmente, existe otro indicador externo que reconoce la educación de calidad e integral que entrega el colegio Santa Isabel de Hungría; es el SNED -Sistema Nacional de Evaluación del Desempeño- de los establecimientos educacionales, conocido también como establecimientos con excelencia académica. Cada dos años se realiza esta evaluación por parte del Ministerio de Educación y el colegio en estudio lleva 14 años recibiendo tal reconocimiento público. Las entidades que se hacen acreedores a tal clasificación reciben un estímulo económico para sus docentes y asistentes de la educación, el cual se otorga en cuatro cuotas anuales; ello motiva a que los docentes pongan todo su empeño en mejorar constantemente.

\section{CONCLUSIONES}

Al llegar al final de este estudio de caso, el autor piensa haber cumplido con el objetivo planteado, que era describir y analizar el Proyecto Educativo Institucional del Colegio Santa Isabel de Hungría para verificar si perseguía el desarrollo de una educación integral. Se comprobó que, basado en el humanismo cristiano y el concepto de persona, como ser compuesto de cuerpo y espíritu, único e irrepetible, sí respondía a una educación integral, especialmente en lo valórico; la figura $\mathrm{N}^{\circ} 1$ así lo demuestra. Se entregaron los orígenes de la entidad sostenedora, la Congregación Religiosa Hermanas Franciscanas Cooperadoras Parroquiales, y a la historia del colegio fundado en 1961, el cual ha pasado por tres importantes etapas, las cuales fueron descritas; el carisma franciscano asumido por esta congregación está plasmado en su PEI -Proyecto Educativo Institucional-. Finalmente, se realizó el análisis de las evaluaciones internas y externas de los últimos 20 años y se pudo constatar que el establecimiento ha mejorado sustantivamente en infraestructura, implementación de medios pedagógicos y perfeccionamiento de los docentes, todo lo cual ha conducido que las evaluaciones externas muestren avances significativos en las pruebas SIMCE y PSU, tal como lo demuestran las tablas $\mathrm{N}^{\circ} 1, \mathrm{~N}^{\circ} 2 \mathrm{y} \mathrm{N}^{\circ} 3$, como asimismo, el reconocimiento por parte del

\footnotetext{
${ }^{14}$ Datos provisorios aún no consolidados, pues las pruebas y sus resultados se dan a fines de año.
} 
Ministerio de Educación al otorgar el SNED por 14 años. Los padres, apoderados y alumnos también se sienten gratos con la labor desarrollada por el colegio, pues siempre se copa su matrícula y los presidentes del centro de padres y del centro de alumnos en el Consejo Escolar lo expresan muy sentidamente.

El establecimiento educacional cumple también con los deseos de la Fundadora, Madre Teresa Ortúzar y lo expresado en su PEI: atender a niños, niñas y jóvenes carenciados; lo demuestra la vulnerabilidad de las familias que son atendidas en el colegio y que este ha vuelto a ser gratuito para atender mejor al grupo beneficiario.

\section{FUENTES BIBLIOGRÁFICAS}

CAICEO, Jaime. Antropología Filosófica y Doctrina Social Cristiana. $2^{\mathrm{a}}$ ed. Santiago de Chile: Ediciones Instituto Profesional de Estudios Superiores Blas Cañas, 1989.

CAICEO, Jaime. Proyecto Educativo Cristiano: Fundamentos Antropológicos, Educativos y Sociales. Santiago de Chile: Ediciones Facultad de Educación, Universidad Católica Blas Cañas, 1996.

CAICEO, Jaime. Economía, Finanzas y Educación. Santiago de Chile: Facultad de Humanidades, Universidad de Santiago de Chile, 1997.

CAICEO, Jaime. Presencias de la Iglesia y el Estado Chileno Republicano en el Sistema Educativo. In: CARVALHO, Carlos Henriques de; GONÇALVES NETO, Wenceslau (Orgs.). Estado, Igreja e Educação: o Mundo Ibero-americano nos Seculos XIX e XX. Campinas: Editora Alínea, 2010ª pp. 265-299.

CAICEO, Jaime. Huellas de Amor de una Mujer Chilena: Congregación Religiosa Hermanas Franciscanas Cooperadoras Parroquiales - Colegio Santa Isabel de Hungría. Santiago de Chile: Ediciones Colegio Santa Isabel de Hungría, Imprenta Madrid, 2010 b.

CAICEO, Jaime. El Colegio Santa Isabel de Hungría en su Cincuentenario: de una Inserción en Comuna Semi-Rural ha pasado a Comuna Urbana. Revista HISTEDBR On-line, $\mathrm{N}^{\circ} 71$, jan./mar, Universidade Estadual de Campinas, Brasil, pp. 5-19, 2017.

CAICEO, Jaime. Filosofía Franciscana: Principales Autores en sus Textos. $2^{\mathrm{a}}$ ed. Santiago de Chile: Ediciones Colegio Santa Isabel de Hungría de la Congregación Religiosa Hermanas Franciscanas Cooperadoras Parroquiales - Ministerio de Educación, Fondos SEP. Imprenta Madrid, 2018.

CANALES, Manuel. Reforma Educacional Chilena de 1965. Revista de Historia de la Educación, vol. 3, Santiago de Chile: Ediciones Sociedad Chilena de Historia de la Educación, pp. 87-103, 1997.

CONFERENCIA Episcopal Española. Sagrada Biblia. Madrid: Biblioteca de Autores Cristianos -BAC-, 2014. 
ESCUDERO, J.C.

CONGREGACIÓN Religiosa Hermanas Franciscanas Cooperadoras Parroquiales. Colegio Santa Isabel de Hungría. Anuario. Santiago de Chile: Ediciones Colegio Santa Isabel de Hungría, Imprenta Madrid Ltda. (Publicación anual ininterrumpida), 2010-2018.

CONGREGACIÓN Religiosa Hermanas Franciscanas Cooperadoras Parroquiales. Colegio Santa Isabel de Hungría. Proyecto Educativo Institucional. Readecuación y Actualización. Santiago de Chile: Ediciones Colegio Santa Isabel de Hungría, Imprenta Madrid Ltda, 2016.

COLEGIO Santa Isabel de Hungría (2005-2018). Informes sobre Rendimiento Escolar. Santiago de Chile: Documento anual elaborado ininterrumpidamente.

COLEGIO Santa Isabel de Hungría. Actas Consejo Escolar. Santiago de Chile: Cuatro documentos anuales de Consejos elaborados ininterrompidamente, 2005-2018.

COLEGIO Santa Isabel de Hungría. Memoria. Santiago de Chile: Documento anual elaborado ininterrompidamente, 1998-2017.

DIÓCESIS DE SAN FELIPE de Aconcagua. Libro de Decretos. San Felipe: Archivo Diocesano, 1925-1950.

FRANCISCO, Papa. Laudato Si. Santiago de Chile: Ediciones San Pablo, 2015.

MUÑOZ, Hermana Mercedes, hfcp. Entrevista, realizada en Los Andes por Myriam Retamal el 24 de julio de 2002.

OLIVARES, Fray Luis o.f.m. Monseñor Roberto Bernardino Berríos Gaínza, Príncipe de las Cosas Simples. Santiago de Chile: Editorial E.D.B.S.A., Serie Testigos de Nuestra Fe, 1995.

PÍO XII, Papa. Radiomensaje 'Benignitas et Humanitas' en la Víspera de Navidad. El Vaticano, 24 de diciembre de 1944 en http://w2.vatican.va/content/piusxii/es/speeches/1944/documents/hf_p-xii_spe_19441224_natale.html. Consultado el 24 de diciembre de 2018.

SOCÍAS, Estela. Un Camino a la Santidad. La Vida de la Madre Teresa Ortúzar Ovalle. Santiago de Chile: Ediciones Colegio Santa Isabel de Hungría, Imprenta Madrid, 2010.

\section{SOBRE O AUTOR}

Jaime Caiceo Escudero é doutor em Ciências da Educação pela Pontificia Universidad Catolica Argentina Santa Maria, de Buenos Aires. É docente do Departamento de Educação da Universidade de Santiago de Chile.

E-mail: jcaiceo@hotmail.com 